\title{
Cidades, águas e ilhas no estuário amazônico
}

DOSSIER RIOS E CIDADES

\section{Leila Mourão Miranda}

Professora/Pesquisadora Associada IV da Faculdade de História e do Programa de Pós Graduação em História Social da Amazônia da Universidade Federal do Pará. Belém [PA] Brasil.

$<$ miranda.mourao@bol.com.br>.

\section{Resumo}

Este texto é derivado das pesquisas que venho desenvolvendo na última década na Linha Historia e Natureza sobre a temática 'Sociedade e Natureza - Saberes e Usos' na região estuarina da Amazônia com a finalidade recuperar memórias e histórias dos processos de interação entre sociedades, águas e insularidades das cidades estuarinas. Os indígenas habitadores da região que atualmente denominamos "estuarina" eram referidos por outras etnias, a época dos contatos com os europeus, como "povos das águas".

\section{Palavras-chave}

Amazonia, história, natureza, estuário, saberes e usos.

\section{Cities, waters and islands in the Amazon estuary}

\begin{abstract}
This text is derived from the researches I have been developing over the past decade on the subject History and Nature, under the thematic "Society and Nature - Knowledge and Uses" in the Amazon estuary, in order to recover memories and stories of the interaction processes between societies, water and insularities of estuarine cities. The indigenous habitants of the region currently called "estuary" were referred, by other ethnic groups, to the time of contact with Europeans, as "people of the waters".
\end{abstract}

\section{Keywords}

Amazonia, history, nature, estuary, knowledge and uses. 
Este texto é derivado das pesquisas que venho desenvolvendo na última década na Linha Historia e Natureza sobre a temática 'Sociedade e Natureza-Saberes e Usos' na região estuarina da Amazônia (Figura 1) com a finalidade recuperar memórias e histórias dos processos de interação entre sociedades, águas e insularidades das cidades estuarinas.

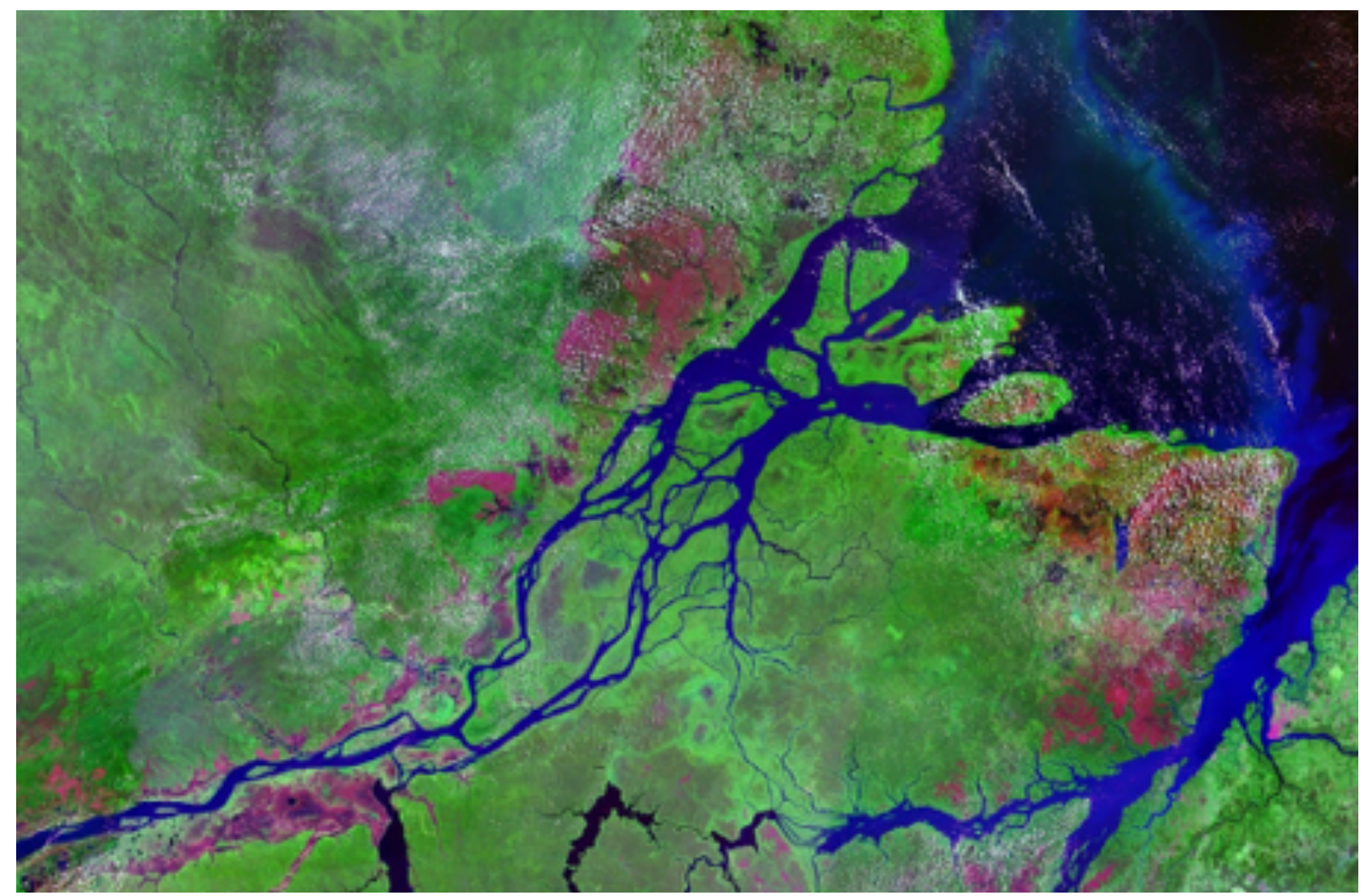

Figura 1. Estuário Amazônico. Fonte: [Imagem: Mouths of amazon geocover 1990. png|thumb|180px|Legenda].

Os indígenas habitadores da região que atualmente denominamos 'estuarina' eram referidos por outras etnias, a época dos contatos com os europeus, como "povos das águas". Segundo Bruzzi (1977) a nomeação das coisas e dos grupos humanos feita pelos indígenas era e é através de nomes, que indicam uma estreita integração ao ecossistema onde viviam ou vivem, e por isso referiam-se às tribos da região do estuário como I'DE-NASÃ (povo da água), assim como as malocas em que habitavam, cuja toponímia era tão indicativa quanto os nomes dos grupos/tribos.

As referências iniciais da área em que está situada a Região Metropolitana de Belém - RMB indicam que ela era habitada por indígenas designados pelo termo genérico de tupinambás. Hurley (1940) citando a crônica de André Temudo informa a existência das aldeias de Parauassú, Guamiaba e Capim onde se localiza a cidade.

Belém do Pará, a cidade símbolo, enquanto "Portal da Amazônia", apresenta características singulares. É a principal região metropolitana da Amazônia. E historicamente tem sido o principal centro de trocas, irradiação de cultura e modos de vida e de viver. Seu território compõe-se de ilhas e parte do continente banhados de águas, caracterizando sua natureza ribeirinha. As ilhas representavam $69,42 \%$ de sua área municipal. Em 1994 ocorreu o desmembramento da sua área em outro município e remanejamento de algumas ilhas. A área insular reduziu-se para $65,64 \%$, mas a sua insularidade continua a representar cerca de dois terços de seu território ${ }^{1}$. Esta condição singular apresenta-se de forma complexa e aparentemente contraditória. A cidade como símbolo e representação mental e material da modernidade, foi organizada historicamente de costa para as águas e ilhas. E como tal tornou-se referência material e imaginária para as outras cidades ribeirinhas na Amazônia.

\footnotetext{
${ }^{1}$ Companhia de Desenvolvimento e Administração da Área Metropolitana de Belém (CODEM) Lei Nº 7.682/1994.
} 
Os habitantes da parcela continental de Belém percebem e vivem na perspectiva de habitar a terra firme, 'fora' das águas e do que elas podem representar.

Os moradores das ilhas estruturam e organizam sua vida e sociedade em função das águas e das insularidades. Elas são os seus caminhos e lugares de territorialidade de seus moradores. As ilhas, neste sentido, são os lugares de morar, de viver, de lazer, de produzir e reproduzir socialmente. Em termos da memória coletiva, simbolicamente as ilhas e seu entorno - as águas - significam e representam o seu lar.

A água tem sido objeto de estudos na perspectiva de recuperar e registrar os diversos modos de interação entre sociedade e natureza, em especial da Antropologia, Filosofia, dos estudos literários e das ciências da Natureza.

Sua incorporação nas interpretações historiográficas tornou-se relativamente abundante no século $\mathrm{XX}$, em especial relacionadas às temáticas relacionadas à abastecimento e higienização de água potável.

Os trabalhos de Diegues $(1998 ; 2000)$ apontaram para as ciências humanas novas possibilidades de abordagens, investigações e interpretações. A historiografia brasileira tem abordado a água, insularidade e ilhéus, mas de forma pontual e principalmente, em relação a outras regiões do país. A literatura também tem dado especial atenção ao estudo das águas, ilhas e cidades como representação poética e narrativas ficcionais.

As águas são prenhes de significados em todo o Planeta, é um elemento da vida e morte que "encompassa" e evoca múltiplos aspectos materiais e imaginários ${ }^{2}$. É condição básica e vital para a produção e reprodução social e natural, mas se inscreve preferencialmente no domínio do simbólico, originando imagens e significados diversos, os quais se manifestam nos ritos, nas cerimônias sagradas ou profanas, nas práticas socioeconômicas e culturais (agrícolas, pesqueiras, alimentares, lazeres, climáticas etc.), entre outras. É impalpável, simbólica e material, embala sonhos, esperanças, mas também dores, tristezas e saudades. É fonte de inspiração poética, de temores e horrores.

A água está em todos os nossos atos, na gestação, na vida e na morte, move e umidece o real, em especial dos que vivem nos trópicos.

Na perspectiva cientifica a água é estudada sob duas dimensões principais: a das ciências da Natureza e a ciências humanas. Nas primeiras a água é concebida em si mesma, como um líquido incolor, sem cheiro e forma, formada por uma molécula composta de dois átomos de Hidrogênio e um de Oxigênio, é um óxido de Hidrogênio. Há que registrar que alguns grupos de pesquisa têm incorporado en seus trabalhos aspectos da dimensão social das águas, mas com maior evidência em seus aspectos utilitários relacionados à higiene e saúde. Atualmente novos problemas sobre a água se colocaram para os cientistas da natureza, como os limites da água doce do Planeta e o elevado grau de sua deterioração e/ou desperdício, suscitando debates, novas pesquisas, formulação de instruções normativas sobre sua finitude, importância social e econômica para a 'humanidade'. De certo modo recolocando a perspectiva social da água sob outras dimensões de investigação e interpretação, que de certo modo os remete ao diálogo com as etnociências e as ciências socioambientais (DIEGUES, 2007). 0 que sobre certos aspectos tem provocado os historiadores ambientais e resultado em importantes contribuições historiográficas nas quais as investigações, de certo modo têm evidenciado a água e suas diferentes formas de existências - mares, rios, lagos, igarapés, canais, lençóis freáticos etc.- como agentes históricos.

Nas ciências humanas, em particular nas literárias, a água se insere do domínio da vida material e espiritual (mental) e, portanto dos símbolos e representações, originando diferentes imagens e significados na perspectiva econômica, social, ambiental e na do imaginário social, político e cultural.

\footnotetext{
${ }^{2} 0$ termo encompassa, de origem inglesa, significa incluir no âmbito de uma dada totalidade, em especial em relação à noção de território. In: OXFORD Advanced Learner's Dictionary of Currente English, Oxford New Press, 2010.
} 
Esses significados diferem no tempo e entre as sociedades e/ou grupos sociais. Neste sentido a água está na Natureza e nas Culturas ao mesmo tempo. E como tal é parte integrante dos mitos e da história. Está na noite e no dia, nas estações do ano, na celebração da vida e da morte, nas cerimônias de nascimento / chegada e de morte / adeus.

Nessa segunda percepção e configurações a água tem cheiro, gosto e cor: são límpidas ou sujas, doces ou salgadas, brancas ou turvas (águas claras e águas pretas de nossos igarapés e rios). Constitui-se como símbolo de dualidade, em especial do alto e do baixo (chuva, rios e similares), do masculino e feminino, do claro e escuro, da vida e da morte (CUNHA, 2000). É também expressão de beleza e encantamento, portanto elemento de contemplação e veneração. É também caminho, via de chegada e de partida.

A água como construto simbólico, prenhe de significados, ambivalências e/ou oposições não representa apenas virtude, beleza, purificação e liberdade, é fonte de criação, de vida e de morte, e como tal, o seu significado pode provocar o medo, pavor ou horror, a punição e a morte. Dentre todas as significações da água, duas se destacam na cultura ocidental: a positivação da água que se insere na cosmologia bíblica, no mito da origem da criação, relacionando-a ao Éden como "o Paraíso", e a sua negativação se vincula a ideia de Dilúvio punitivo e purificador.

Mas, a água é essencialmente percebida e assimilada como lugar de passagem, de travessia e as ilhas nela existentes, como locais de paragem, e nem sempre de fixação.

Diegues (1998) em 'Ilhas e Mares: simbolismo e imaginário' ressalta as percepções e interações que se estabelecem com as águas são diversificadas e que:

[...] Nem todas as sociedades insulares, no entanto, desenvolveram práticas sociais $e$ simbólicas que constituem a maritimidade. Algumas delas se constituíram historicamente de costas para o mar, ao passo que outras, inicialmente nessa condição, passaram, numa fase subsequente, a constituir a sua maritimidade (DIEGUES, 1998, p.53).

Na Amazônia as cidades em seus primórdios, como em todo o Brasil, nasceram às margens das águas e mesmo as construídas na segunda metade do século XX, nas ditas "beiras de estradas", se localizam também, às proximidades de um rio ou riacho, mas sempre "de costas".

A literatura brasileira apresenta a semelhança dos países europeus ocidentais, a noção de águas e ilha como lugares de sonhos e fantasias, de domínio mítico e sobrenatural. E como rebatimento desse imaginário as águas se tornaram caminhos e as ilhas são ainda percebidas como um lugar de isolamento e de reclusão. Os seus significados universais de lugares de passagem e paragem revestem-se de uma condição especial que as tornam uns prováveis locais para realizar desterro. Foi a partir desses sentidos e significados que se elaboraram formas de utilização das águas ilhas na Amazônia e inicialmente as da atual Região Metropolitana de Belém.

Na época da conquista ibérica a identificação inicial de que as terras achadas seria uma ilha, possibilitou o envio de criminosos de todos os tipos por parte das cortes europeias. A colonização da Amazônia não fugiu a regra geral.

A documentação relativa aos séculos XVII ao XIX ao se referirem às águas e ilhas que compõe a RMB e seus arredores trazem informações indiciárias, de elas que eram utilizadas para instalação de faróis ou sinaleiras para orientar a navegação. Mas também eram lugares de pesca, fugas, esconderijos e ou moradias de indígenas, escravos africanos, afros descentes e outros fugitivos. Encontra-se, ainda que as águas e ilhas ou parte delas, foram concedidas em Cartas e Data de sesmarias, ao longo dos últimos três séculos. Os registros informam também, que a maioria das ilhas e várzeas foi aproveitada para os cultivos ameríndios de mandiocas, árvores frutíferas, urucum, algodão e espécies madeireiras e medicinais. E após a chegada dos europeus elas serviram para plantações de cana-de-açúcar, cacau, arroz, urucum, baunilha etc. Suas margens tornaram sede de olarias, engenhos e engenhocas, vilas e cidades. Encontra-se que nessas áreas ainda que, houvesse moradores/habitadores, de modo geral eles foram relativamente ignorados pelo poder

MIRANDA, L.M.. Cidades, águas e ilhas no estuário amazônico. Labor \& Engenho, Campinas [SP] Brasil, v.9, n.2, 
público, pois com raras exceções os "proprietários" viviam nas cidades.

No final do século XIX as águas e as ilhas estuarinas foram sendo reconhecidas incorporadas como territórios administrativos. A Baía do Guajará e o Rio Guamá foram apropriados juridicamente, como vias de navegação e de localização dos principais portos de chegada e saída de mercadorias.

E algumas ilhas foram sendo povoadas através de projetos de governo, em função da política de imigração por ele promovida, em especial as maiores como Caratateua, Onças, Mosqueiro, Cotijuba, etc.. A par dessas ações, a ocupação desautorizada, de outras ilhas de menor importância (Combu, Ilha Grande), por migrantes nordestinos, recusados nos projetos governamentais relativos à produção do látex, ou que vinham por conta própria para a Amazônia, sem condições financeiras para chegar aos seringais ou castanhais.

A ilha de Arapiranga, atualmente compondo o munícipio de Barcarena, foi utilizada como lazareto e para quarentena de doentes com varíola.

No século XX se elaborou uma nova percepção e significado sobre algumas dessas ilhas - o de importante área de turismo e lazer (veraneio) ou de prisões e as águas como caminhos e depositório de resíduos oriundos da cidade e embarcações.

As ilhas de Outeiro, Mosqueiro, Onças e algumas outras se tornaram locais favoritos para a elite estrangeira e os novos enriquecidos pela extração e comercialização do látex, da castanha e das madeiras, mas a Ilha de Cotijuba notabilizou-se como prisão política entre 1931 e 1978.

As ilhas que atualmente compõem a RM de Belém só começaram a passaram a ter certa atenção sistemática do poder público a partir da década de 1970. Os motivos foram diversos: denúncia de ambientalistas, ações dos movimentos sociais organizados de moradores, em algumas ilhas, reivindicando melhoria de transporte, construção de escolas, postos de saúde etc. Acrescenta-se que no caso de Mosqueiro o esforço para a construção de uma via terrestre, com a finalidade de facilitar o acesso ao principal e mais próximo lugar de veraneio, promoveu a valorização das propriedades rurais ao longo da mesma, obtendo o apoio de seus proprietários. 0 mesmo ocorreu em relação à ilha de outeiro na década de 1980.

A Região Metropolitana de Belém está situada no estuário amazônico, identificado como área de influência das marés atlânticas. 0 estuário é formado pelas desembocaduras do rio Amazonas, dos rios Tocantins, Pará, Moju e Guamá, aos quais se somam as de rios de menor volume, desde o Cabo do Norte (Amapá) até ao litoral Nordeste do Pará (Rio Gurupi na divisa com o Estado do Maranhão). Toda essa região costeira encontra-se pontilhada de centenas de ilhas, entre as quais se destacam as ilhas do Marajó e a do Gurupá. Na região costeira oriental, a foz do Amazonas é identificada com o litoral do Amapá e o litoral do Pará.

Belém localiza-se na típica região estuarina, conformada pelo Estuário Guajarino que integra o Golfão Marajoara, cujo ambiente fluvial é formado na confluência dos rios Pará, Acará e Guamá. Constitui-se de uma parte continental e uma região insular separada por rios (Mari-Mari, Pratiquara, Morubira, Maracacacuera, Arari, Paraíba e Guamá); furos (Maguari, dos Bragas, Cotovelo); igarapés (Ananindeua, 40 Horas, Bacuri, Icuí-Guajará, São Joaquim, Tucunduba, das Armas, Val-de-Cães, da Fome, Gagé, Aurá e outros); canais de maré, que configuram entre as ilhas de Mosqueiro, Outeiro ou Caratateua (Barreiras), Jutuba, Paquetá-Açu, Urubu-Oca, Cotijuba, Cumbu, Marituba, São Pedro, Roldão, Papagaios entre outras; e pelas baias de Guajará, além dos lagos Utinga, Água Preta e Bolonha.

Configurando-se às margens da baia de Guajará e do rio Guamá, a cidade de Belém possui clima do tipo Af, com temperatura média de $30^{\circ} \mathrm{C}$, pluviosidade média de $2.500 \mathrm{~mm}$, com solos hidromórficos do tipo Glei pouco húmido. Formada de terras continentais e ilhas está sob a influência das marés, apresenta ainda algumas áreas de matas de várzea, dominadas por açaizais, manguezais, cipoais e poucas árvores de grande porte, com sub-bosques relativamente fechados nas ilhas e em alguns bairros onde há, ainda, grandes áreas institucionais e na periferia.

As ilhas que compunham o território Belém variaram em número ao longo dos séculos XIX e XX. O

MIRANDA, L.M.. Cidades, águas e ilhas no estuário amazônico. Labor \& Engenho, Campinas [SP] Brasil, v.9, n.2, 
Instituto Brasileiro de Geografia e Estatística-IBGE identificou e qualificou quase uma centena de ilhas nas proximidades de Belém, entretanto em face ao desmembramento de seu território em outros municípios, parte destas ilhas passaram aos novos municípios instituídos, como os de Barcarena, Acará, Ananindeua, Santa Bárbara, Marituba e Benevides. Segundo com a Companhia de Desenvolvimento e Administração da Área Metropolitana de Belém (CODEM), em 2011 foram catalogadas quarenta e sete (47) ilhas na região Metropolitana. 0 instrumento administrativo, que redefiniu os limites municipais, indica as trinta e nove (39) ilhas que compõem o termo administrativo do território do Município de Belém, as outras nove comporiam os termos dos que foram desmembrados ${ }^{3}$.

Buscar, recuperar e recolocar a história das cidades estuarinas, com o foco em Belém, incorporando a sua insularidade e suas águas, se constituiu o objetivo geral da nossa pesquisa. Trata-se do esforço de elaboração de uma história ambiental da RM de Belém na perspectiva de estabelecer o diálogo necessário, entre o presente e o passado, de modo a tornar inteligíveis os saberes, fazeres e usos, que a sociedades e grupos, em sua diversidade e complexidade. Na medida em que os que nele habitam e vivem elaboram e constroem em suas diferentes "cidades imaginárias e reais" na cidade. E expressam ambientes, percepções, apropriações e representações de cidadania, espacialidades e temporalidades, que os termos normativos da ciência, da justiça, do calendário e do território administrativo, préestabelecidos, não dão conta e não contam a História.

Impõe-se nesta abordagem a profícua multi e interdisciplinaridade com as diversas áreas do conhecimento. 0 que requer a adequação de metodologias, possibilitando que os diálogos pertinentes entre o passado e o presente, sociedade e natureza, percepções e representações, memórias e história do processo histórico de construção de cidades na Amazônia, se torne inteligível. Captar, recuperar e tornar conhecida a cidade insular e suas águas na realidade, na imaginação, na sensibilidade, no social, relativizada nas percepções e representações que resultam das e nas alteridades dos ambientes e dos grupos sociais que vivem e convivem nelas, foi o que orientou o presente texto.

As cidades resultam de processos de interação entre Sociedade e Natureza e são resultantes de múltiplas ações antrópicas. São lugares de aglomerações humanas; de produção e reprodução social e cultural; de construção, desconstrução e reconstrução do urbano; de centralização de trocas, de abastecimento, distribuição e consumo; de nascer, viver, morar e morrer; de percepções, apropriações, significações e representações distintas.

O estudo da cidade constitui-se em tema complexo e diversificado e requer uma interpretação inter e multidisciplinar. Os temas a ela pertinentes são variados e requerem uma gama de conhecimentos que individualmente seriam impossíveis de acumular ao longo de uma vida, principalmente pela formação monodisciplinar de cada especialista. Para a abordagem histórica a diversidade de possibilidades se coloca e aponta inúmeras dificuldades para os profissionais da área, resultando muito mais em historiografia pontual sobre um aspecto da cidade, da água de uma bacia, ou uma ilha. A cidade continental e a insular, como espaço, território urbano e rural ainda não foi abordado na historiografia.

A atração da história pela cidade explica-se pelo fato da mesma (do urbano) se impor, como relevante, em relação à distribuição da população, das atividades socioeconômicas, políticas administrativas e culturais no espaço físico e no tempo, por um lado. E por outro, a sua perenidade em relação à história humana a coloca nos movimentos históricos de longa duração, como centro de elaboração e irradiação de cultura. Nesta perspectiva, o conceito de cidade engloba a noção da Polis grega, da Civita romana, da Urbe moderna e das Metrópoles contemporâneas.

Na historiografia sobre a Amazônia brasileira a(s) cidade(s) e seu desenvolvimento histórico tem sido analisado de forma subjacente à história dos atos normativos de implantação do sistema político administrativo colonial e demais.

\footnotetext{
${ }^{3}$ Companhia de Desenvolvimento e Administração da Área Metropolitana de Belém (CODEM) Lei N 7.682/1994. Em 2011 com a definição dos limites territoriais entre o Município de Belém e Ananindeua, oito ilhas, das quarenta e sete catalogadas, foram transferidas para os termos administrativos dos territórios dos Municípios de Ananindeua e Santa Bárbara.
} 
No apossamento da Amazônia brasileira duas concepções básicas orientaram o surgimento das cidades: a defesa e a conquista das posses territoriais e a ocupação civilizatória. As primeiras tiveram a finalidade de assegurar a presença da administração metropolitana e servirem de referência para a irradiação da cultura civilizatória europeia. E as segundas surgiram em lugares de agrupamento dos ameríndios, onde seriam educados, disciplinados para o trabalho, ou seja, civilizados, em especial com a instituição das missões. E passariam a ser, após esse processo, também, locais de disseminação de uma nova ordenação socioeconômica e cultural. 0 primeiro objetivo da criação de aglomerações urbanas foi o bélico, o que explica a localização da maioria delas no grande estuário amazônico. 0 segundo foi o de apropriar-se explorar economicamente e culturalmente a região e os grupos humanos que nela habitavam.

Seguindo a tradição europeia, as cidades na Amazônia, até a segunda metade do século XX, se localizaram junto às águas dos rios, furos, igarapés e lagos. A partir da década de 1960 as cidades foram implantadas ao longo das rodovias para promover o 'desenvolvimento e a integração' do chamado 'Brasil Central', mas ainda nas proximidades de 'recursos hídricos'.

De acordo com os estudos de História Urbana de Benévolo (1983), as cidades já na antiguidade clássica se desenvolveram junto às águas na Mesopotâmia, no Mediterrâneo, assim como no extremo Oriente. No mundo medievo ocidental, as cidades europeias, que cresceram a partir de antigos traçados urbanos também eram recortadas pelas águas. No Renascimento o ideário sobre a cidade utópica foi pensado em estreita relação com a água. A cidade-ilha 'Utopia' idealizada por Thomas More expressa essa perspectiva: "Em todo o espaço compreendido entre a cidade e o mar, e algumas milhas acima da cidade, o fluxo e o refluxo, que duram seis horas por dia, modificam singularmente o curso do rio" (MORE, 1996, p. 75).

A história das cidades elaborada entre os séculos XV e XVIII perfilou na defesa da originalidade da comunidade citadina como portadora da civilização e por consequência, campo propício para a realização da racionalidade científica e da ordenação civil sob os auspícios da fé. Para Roche (1978) nesse período:

[...] A história do urbano é simultaneamente ocasião para que as ordens religiosas, atentas aos trabalhos da inteligência, desenvolvam uma abundante produção dedicada à celebração da civilização urbana, encarada no esplendor das instituições, na grandeza do espetáculo social e nos fausto da festa citadina (ROCHE, 1978, p. X).

O processo de apreensão e explicação da realidade pelas diversas sociedades e grupos sociais, ao dar ênfase a elaboração de imagens, que antecedem às ideias e conceitos, são construídas através do processo de conhecimento. As imagens são construídas historicamente, expressam uma mistura de desejo e visões, isto é, de representação de sentimentos e forças da natureza. Representam níveis de compreensão, em nível do imaginário, das imagens naturais, fornecidas pela natureza e são percebidas a partir de referenciais que lhes dão significados e significância, criando e recriando os sentidos da relação Sociedade-Natureza.

A historiografia das cidades no Brasil orientada por modelos paradigmáticos emprestados das ciências naturais até muito recentemente, tiveram no racionalismo cartesiano e no empirismo baconiano as suas bases, consolidando-se no positivismo evolucionista do século XIX, produziram histórias das cidades na perspectiva da narrativa dos atos políticos administrativos ordenadores, higienizadores e modernizadores. Decorre de tal perspectiva a predominância de estudos sobre o abastecimento de água potável e de eventos a ele relacionados.

A ideia de que as cidades coloniais brasileiras surgiram de forma espontânea e desorganizada vem sendo revista. Segundo Santos (2001), as primeiras cidades americanas chegaram concebidas e prontas:

[...] Os portugueses trouxeram regras claras para definir público e privado, para localizar equipamentos, [...] Os funcionários que vinham fundá-las traziam orientações estritas: Casa da Câmara aqui, igreja ali, adiante fortaleza e colégio (SANTOS, 2001, p.39).

A conquista e a colonização do continente americano foram em parte orientadas pelo simbolismo imaginário medievo, na construção de sistemas simbólicos de segurança, no qual as águas eram portadoras de monstros, seres indescritíveis e forças inexplicáveis, punitivos e vingativos. Essa

MIRANDA, L.M.. Cidades, águas e ilhas no estuário amazônico. Labor \& Engenho, Campinas [SP] Brasil, v.9, n.2, 
imagem das águas impregnando o imaginário colonial orientou, também, a localização das cidades e o seu crescimento. Durante quase três séculos, ainda que as cidades fossem fundadas a beira das águas, em especial no Brasil e na Amazônia, o seu crescimento sempre foi para o interior do continente.

A positivação cultural das águas, em particular dos mares ocorreu a partir da Renascença, no século XVII, quando ele se tornou elemento de encantamento, beleza, objeto de prazer, desejo e emoção.

O modelo de organização das povoações colonizadoras era transposto da metrópole: construção dos edifícios públicos para administração e defesa, os templos católicos, as ruas retilíneas, as margens das quais deviam ser construídas as edificações (habitações, comércios e outros) totalmente fechadas. A utilização desses ambientes tinha regras definidas a priori, que não se quadunavam com as práticas e os saberes ameríndios na região. Nessas povoações, o processo histórico se estruturou em torno de intensa competição, resistência e luta em que os grupos sociais e étnicos distintos, disputaram espaço e recursos naturais, sempre associadas aos cursos das águas, por um lado. E por outro elaborou concepções ou modos específicos de se apropriarem simbólica, econômica e socialmente deles, na perspectiva de realizarem ali a sua cultura.

A correspondência entre a metrópole e a colônia dava conta da decadência dessas povoações e atribuíam à falta de cultura e civilização dos nativos e à floresta, o insucesso na criação das 'cidades' em face às águas que as circundavam. As referências a São Luís do Maranhão e Santa Maria de Belém do Grão Pará, no período não fogem a regra.

Na segunda metade do século XIX a modernização das cidades efetuou-se nos projetos urbanísticos sanitaristas e higienizadores. E a historiografia passou a privilegiar em suas interpretações o espaço construído, a tecnologia e o estilo, ou na linguagem de Vitruvio: "comodidade, solidez $e$ beleza". Objetivava reafirmar a cidade como centro produtor, reprodutor e irradiador da civilidade e da cultura e a positivação da racionalização ordenada e estética da cidade moderna. Historicizase o que habita na cidade, ou os aspectos da cidade que se tornaram monumentais ou pitorescos. Resgatam-se alguns signos em forma de símbolos, para tornarem-se referência do novo.

No século XX a historiografia que se renovava passou a valorizar os aspectos econômicos, sociais, culturais e ecológicos das cidades, ampliando significativamente suas possibilidades interpretativas e seus horizontes de investigação: a natureza e o ambiente, assim como suas transformações, a paisagem natural e a construída; a população e sua composição; a ecologia das ações antrópicas; a literatura, a pintura, a escultura; as edificações, a habitação, os móveis e utensílios; as técnicas e as tecnologias e os saberes; a produção, o trabalho e as relações de trabalho; a alimentação, os alimentos, a comida e a comensal idade; as religiões, a religiosidade e os mitos; o cotidiano; as doenças e os hospitais, a criminalidade e as prisões, as mulheres e a casa, a infância e a escola, a loucura e os hospícios, a saúde e o lazer; a cidade, os jardins, as praças, as ruas, as edificações públicas, entre outros.

Uma análise na produção historiográfica publicada na Revista Brasileira de História consta que ao longo de sua existência foram publicados apenas três dossiês sobre a temática cidade: 1984/1985 (dossiê: Cultura e Cidade), 2003 (dossiê: Experiências Urbanas) e em 2007 (dossiê: Cidades), nenhum sobre a água. Os artigos do primeiro se concentram em torno das transformações urbanísticas ocorridas em cidades; o segundo apresenta um panorama geral de cidades, e o terceiro gira em torno da cultura na e das cidades. De modo geral a história da cidade se constitui em tema subjacente às questões focadas pelos autores.

No que se refere à elaboração historiográfica sobre a cidade avança-se no sentido de apreendê-la como habitat, no sentido de morar, habitar, viver, produzir, trocar, sonhar, criar e realizar, isto é percebê-la e interpretá-la em sua totalidade dialética: material, social, econômica, política, cultural e ecológica.

O processo de percepção, apreensão e explicação da realidade pelas diversas sociedades e grupos sociais dão ênfase ao processo de elaboração de imagens que antecedem às ideias e conceitos, que são construídas através do processamento de conhecimento. As imagens são construídas

MIRANDA, L.M.. Cidades, águas e ilhas no estuário amazônico. Labor \& Engenho, Campinas [SP] Brasil, v.9, n.2, 
historicamente, expressam uma mistura de desejo e visões, isto é, de representação de sentimentos e forças da natureza. Expressam graus de compreensão, em nível do imaginário, das imagens naturais, fornecidas pela natureza e são percebidas a partir de referenciais que lhes dão significados e significância, criando e recriando os sentidos da relação Sociedade-Natureza. Concordamos com Bachelard (1989), quando afirma que [...]

[...] a imaginação não é, como sugere a etimologia, a faculdade de formar imagens da realidade: é a faculdade de formar imagens que ultrapassam a realidade, que cantam a realidade (BACHELARD, 1989, p.18).

Neste sentido as imagens elaboradas da natureza, sociedade e da cidade são expressas por metáforas, como forma de expressão da alma poética. E como tal é uma projeção da natureza humana sobre a natureza universal.

A interpretação da cidade permite múltiplas leituras e resulta em diversidade de imagens e de escritas orientadas por diferentes olhares e opções metodológicas. Arquitetos, antropólogos, geógrafos, sociólogos, jornalistas, economistas, historiadores, poetas, romancistas, fotógrafos, planejadores, políticos estudam e escrevem sobre a cidade - a urbe, a Civita e/ou a Metrópole. A produção bibliográfica sobre cidade é grande e profícua, resultando em múltiplas e diversas abordagens. A historiografia não foge a regra.

Tomando-se como referência as proposições metodológicas da historiadora Pesavento (2002, 2005 e 2007), em se tratando da interpretação da história e memória da cidade e seu entorno, há que pressupor que ela é materialidade, mas também sociabilidades e sensibilidades.

A cidade real, concreta, visual, táctil, conforme a tradição é composta de ruas, avenidas, travessas, alamedas, vilas, edificações, praças, monumentos, águas, pontes, portos, fontes e ruínas entre outros componentes, que passam a constituírem-se em lugar e lugares, representa a sua materialidade. Essa cidade é a construída com taipa, pedra, cal, tijolos, cimento, concreto, madeira, telha e água, além de outros materiais, por engenheiros, arquitetos e muito trabalho de homens comuns.

Em tese é a cidade que possibilita o morar, o viver, o trabalhar, o nascer e o morrer, ou seja, o habitar em sentido 'pleno'. Mas as cidades situadas na RM de Belém contém outras cidades, em que os rios, canais e igarapés são as ruas; as vilas, templos e o comércio construídos de modo semelhante aos cidade continental (tradicional), convivem com uma vegetação que é confundida com floresta pelos olhares externos e em grande parte dos textos que a descrevem: é a parte da cidade edificada nas ilhas. E que se encontra excluída das histórias escritas sobre Belém. É necessário conhece-la e incorporá-la na historiografia.

A essas cidades concretas correspondem outras cidades - as imaginárias de cada um - sonhadas, desejadas, amadas, temidas e odiadas: representações icônicas construídas por atores, relações sociais, pessoas, grupos, classes, práticas de interação e oposição, submissão e resistências, de ritos e festas, costumes, hábitos e comportamentos que se expressam numa cidade-sociabilidade. Nesse sentido a representação da cidade é fruto de pensamento, portanto, sensível, percebida pelos sentidos e sentimentos e imaginada pelas emoções. É a cidade construída pelo pensamento que identifica, classifica e qualifica o traçado, a forma, o volume, as práticas e usos, os seus viventes, o vivido e o visível tangível.

Sobre a cidade real e a imaginária, ou a partir delas, as de cada um, nela viventes, conforma-se outra, a cidade sensibilidade, que é a construída a partir de atribuições de signos, significados e símbolos que lhe dá sentido no mundo e para cada um de seus habitantes. Esse sentido é que compõe o ethos do urbano de cada pessoa que nele viviam ou vivem. Essa cidade sensível se revela e expressa pela percepção das emoções e dos sentimentos, dados pelo viver de cada um e de todos: as suas utopias, esperanças, desejos, dores, amores, alegrias, tristezas, desamores, temores, medos, invejas, saberes e conhecimento, individuais e coletivos, que o viver, resultante do habitar na cidade propicia. É a cidade percebida, compreendida e expressa da e na sensibilidade, que se considera como lugar do nascer, do viver e do morrer. Sintetiza as identidades do indivíduo e da coletividade 
na sua interação com a urbe e com suas águas.

A cidade sensível responsável pela atribuição de sentidos e de significados do e no seu espaço-tempo é a que se realiza na e pelas cidades reais e imaginárias, transformando-a em lugar-lugares, portadores de significados, de memórias, lembranças e esquecimentos, espontâneos e deliberadas, individuais e sociais. É por isso a cidade do cidadão e do excluído, expressando as diferenças e as alteridades e a construção de novas identidades dos que nela habitam e vivem. Resulta de processos mentais de representação da realidade cotidiana e eventual (história), que despertou emoções e sentimentos, possibilitando a sensação de pertinência e de pertencimento, e de identidade como partícipe, permite inventar e criar passados, viver o presente e construir cenários futuros.

A noção de representação das cidades da RM de Belém aqui proposta é adotada na perspectiva analítica sugerida por Rama (1985) como um termo, que busca dar conta das interações entre 'social e mental' na percepção, apreensão e construção de ideias e imagens sobre a cidade e suas águas, elaboradas para expressar o sentido, que ela tem para cada grupo social nela vivente, agindo e interagindo entre si nos seus ambientes naturais ou construídos.

Buscou-se recuperar a representação construída sobre a cidade recompondo discursos, imagens e práticas sociais do perceber, do viver e pensar a cidade a partir do olhar, do gesto, da cor e da palavra, que qualifica e estabelece dicotomias como progresso/atraso, novo/velho, bonito/feio, bom/ruim e em especial da água/terra firme. Distinguindo-as de sentidos e significados como de velho e antigo, que possibilitam a construção e a internalização de noções de Patrimônio e Preservação a eles relacionados.

Os estudos de Cultura Material constituíram, também, em importante contribuição para a historiografia contemporânea das cidades, na medida em que ao precisar seu objeto de investigação, incorporaram em suas interpretações os processos de interação entre Sociedade, Natureza e Cultura. 0 que possibilitou a reconstrução do conhecimento tecnológico, técnico dos saberes e fazeres, assim como as modificações realizadas pelas diferentes sociedades nos diversos ambientes em que viveram, vive e operam, e por extensão, incorporou os elementos e conceitos de materialidade histórica e de estruturas subjacentes à história de cada uma. Esta perspectiva de interpretação abriu um diversificado leque de possibilidades interpretativas para a história das cidades. Ressalta-se a amplitude das fontes passíveis de utilização, entre as quais as memórias, imagens, edificações, praças, ruas, ruínas e os diferentes ambientes, em suas diferentes versões. Além disso, tornou-se fundamental a percepção dos paradoxos que compõe a cidade, que em essência revelam as distintas cidades, reais ou imaginárias, conformando a História da Cidade e das Águas.

No que se refere a recente produção historiográfica sobre a RM de Belém temas como água, fontes, ilhas, abastecimento, iluminação, saneamento, orla, parques bacias hidrográficas urbanas, entre outros, tem sido abordados e têm resultado em uma nova apreensão e interpretação importantes elementos constitutivos da história da cidade (CRUZ, 1973; MEIRA FILHO, 1978; BENJAMIN, 1995; CARDOSO, 2000; CASTRO, 2006; RODRIGUES, 2006; BRANDÃO, 2006; DERGAN, 2006).

Em relação à bibliografia sobre as águas de seu entorno e sua insularidade tem sido profícua, ainda que sejam resultados de investigações da geologia, geografia, sociologia, ecologia, engenharia florestal, botânica, antropologia, arqueologia e outras áreas de conhecimento. São ainda incipientes os estudos que abordam a cidade em sua complexidade, evidenciando as interações cultura-natureza. Pouco se produziu sobre as águas e a insularidade (ARAÚJO, 1995; MOREIRA, 1966; MEIRA FILHO, 1978; CASTRO, 2006; SILVA, 1995; DERGAN, 2006). Há uma lacuna historiográfica nesses estudos, seja em relação ao passado ou na contemporaneidade da RM de Belém e esta questão se justifica pelos sentidos e significados das águas e ilhas no imaginário, que tem orientado os poderes públicos e a intelectualidade produtora do conhecimento histórico sobre a cidade ${ }^{4}$. A historiografia produzida sobre as cidades da RM de Belém até a década de 1980 privilegiou a historia de sua parte continental5. Essa escrita abordando temáticas específicas, adotando temporalidade e metodologias diversificadas,

\footnotetext{
${ }^{4}$ Sobre a ilha de Mosqueiro foram produzidos trabalhos como os de: BRANDÃO \& DANTAS, 2004; e BRANDÃO, 2006.

${ }^{5}$ Ver, por exemplo: Ernesto Cruz (1945, 1945, 1948, 1952, 1957, 1962, 1970 e 1973); Henrique Jorge Hurley (1940); Arthur Viana (1900), Palma Muniz (1921); Augusto Meira Filho (1976).
} 
tem contribuído no sentido de reconstruir narrativas fundamentais na perspectiva de superar a historiografia focada na ação política administrativa ${ }^{6}$. Contribuição importante para compor a historia da cidade, mas que necessita incorporar as suas águas e insularidade, na medida em que eles são partícipes da Historia.

A historiografia enquanto resultante de processos mentais de representação na escrita busca expressa-la como a cidade visível, material, imaginária e imaginada e a cidade sensível e tornando-se por isso unidades de tempo e espaço de vivências e lugares, histórica e ambientalmente definidos.

Torna-se lugar no tempo, pois é descrita como um espaço com sentidos e significados estabelecidos na temporalidade e como tal revela momentos/tempos no espaço, evidenciando tempo materializado em uma dada superfície do planeta. Nessa cidade esse tempo se constrói a partir do e no espaço construído e não construído, não sendo possível representa-la sem um e outro.

A cidade e as águas como possibilidade de entendimento e representação nessa perspectiva se dão a ver e a serem. A primeira pela sua materialidade arquitetônica e urbanística e a segunda pelas possibilidades de apreendê-la como outras cidades e espacialidade líquida que é, e estão contidas na cidade do presente, enquanto ambivalência de dimensões materiais, ambientais e sentimentais, que se cruzam e entrelaçam.

\section{Referências}

ARAÚJO, José Mariano Klautau. Dimensão Insular. Belém [PA]: (s/ed.) 1995.

BACHELAR, G. A Água e os Sonhos. São Paulo: Martins Fontes, 1989.

BENÉVOLO, L. História da cidade. São Paulo: Perspectiva, 1983.

BRANDÃO, Eduardo Jorge. Mosqueiro: a história de um arquipélago singular no Estuário Amazônico. Ilhas da Amazônia, Belém: s/ed., 2006.

BRANDÃO, Eduardo J. C.; DANTAS, Amauri B. Encantos e Encantamentos em uma ilha do Rio Mar. Belém: s/e., 2004.

BRUZZI, A. A civilização indígena dos Naupés. Roma: LAS, 1977, p. 48-113.

CARDOSO, Maria da Paz Araújo. Ilha de Mosqueiro, cenário de lutas amazônicas na trilha da sobrevivência. Belém: UFPA/CES — Curso de Serviço Social, 2000.

CASTRO, Edna (Org.). Belém de Águas e Ilhas. Belém: CEJUPA, 2006.

CODEM - Companhia de Desenvolvimento e Administração da Área Metropolitana de Belém. Lei Nº 7.682/1994. Belém [PA], 1994.

CRUZ, Ernesto. História de Belém. Belém: UFPA, 1973.

CUNHA, Lúcia Helena de Oliveira. Significados Múltiplos das Águas. In: DIEGUES, Antonio Carlos. A Imagem das Águas. São Paulo: HUCITEC/USP, 2000.

DERGAN, João Marcelo. História, Memória e Natureza: Produção e Reprodução das Comunidades das Ilhas de Belém-j O Caso do Combu. Belém: UFPA/PPHIST, (Dissertação de Mestrado), 2006.

DIEGUES, Antonio Carlos. Ilhas e Mares: Simbolismo e Imaginário. São Paulo: Editora HUCITEC, 1998.

DIEGUES, Antonio Carlos. A Imagem das Águas. São Paulo: HUCITEC/USP, 2000.

${ }^{6}$ Consultar dissertações defendidas no PPGIS/UFPA a partir de 2006. 
DIEGUES, Antonio Carlos. Água e Cultura nas Populações Tradicionais Brasileiras. In: Anais do I Encontro Internacional: Governança da Água - PROCAM/NUPAUB/USP - Gov. São Paulo. São Paulo, nov. 2007.

HURLEY, Jorge. Belém do Pará: sob o domínio português (1616 a 1823). Belém: Oficinas Gráficas da Livraria Clássica, 1940.

MEIRA FILHO, Augusto. Mosqueiro, Ilhas e Vilas. Belém: GRAFISA, 1978.

MORE, Thomas. A utopia. Lisboa: Guimarães Editores, 1996.

MOREIRA, Eidorfe. Belém e Sua Expressão Geográfica. Belém [PA]: Imprensa Universitária, 1966.

MORSE R.; HARDOY, J. E. Cultura urbana latinoamericana. Buenos Aires: Consejo Latinoamericano de Ciências Sociales [CLASO], 1985.

OXFORD. Advanced Learner's Dictionary of Currente English, Oxford New Press, 2010.

PESAVENTO, Sandra Jatahy. Com os olhos no passado: a cidade como palimpsesto. Revista ESBOÇO, n. 11, p. 25-30, 2002.

PESAVENTO, Sandra Jatahy. História \& História Cultural. Belo Horizonte: Autêntica, 2005.

PESAVENTO, Sandra Jatahy. Cidades visíveis, cidades sensíveis, cidades imaginárias. Revista Brasileira de História, v. 27, n. 53, junho de 2007.

POLIÃO, Marcos Vitrúvio. Da Arquitetura (Da Architetura Libri Decem), Tradução de Marco Aurelio Lagonegrogo. São Paulo: Hucitec, 2002.

RAMA, A. La Ciudad Letrada. In: MORSE R. \& HARDOY, J. E. Cultura urbana latinoamericana. Buenos Aires: Consejo Latinoamericano de Ciências Sociales [CLASO], 1985, pp. 11-37.

REVISTA BRASILEIRA DE HISTÓRIA, v. 5, n. 8-9, abril 1984-1985 (dossiê: Cultura e Cidade); v.23, n.46, 2003 (dossiê: Experiências Urbanas); v.27, n.46, jan./jun. 2007 (dossiê: Cidades).

ROCHE, Daniel. Cidades. In.: LE GOFF, Jacques; CHATIER, Roger; REVEL, Jacques (direção). A Nova História. Coimbra: Almedina, 1978.

RODRIGUES, Alcir de V. Alvarez. Narrativas orais da Ilha de Mosqueiro. Belém: UNAMA (Monografia de Especialização), 2006.

SANTOS, Paulo Ferreira. Formação de Cidades no Brasil Colonial. 1904-1988. Rio de Janeiro: Editora UFRJ, 2001.

SILVA, Maria de Jesus Benjamin. Caratateua: A Ilha e o Subúrbio de Belém. São Paulo: USP (Dissertação de Mestrado), 1995. 